\title{
FORMAÇÃO DOCENTE NA PERSPECTIVA DA PEDAGOGIA DAS COMPETÊNCIAS
}

\section{TEACHER'S EDUCATION IN THE PERSPECTIVE OF PEDAGOGY OF COMPETENCIES}

\author{
Amarildo Luiz Trevisan* \\ Professor do Departamento de Fundamentos da Educação do Programa de Pós- \\ Graduação em Educação da Universidade Federal de Santa Maria \\ Dirceu Alberti** \\ Professor da Universidade Regional Integrada do Alto Uruguai e das Missões, \\ Campus de Santiago
}

Resumo: O artigo aborda a formação docente na perspectiva da filosofia da educação, a fim de reconhecer o caráter instrumental presente na Pedagogia das Competências. Desse modo, o objetivo foi analisar quais as possibilidades e os limites das competências para a formação docente na perspectiva da teoria da ação comunicativa, de Jürgen Habermas. O referencial teórico é embasado na abordagem hermenêutico-reconstrutiva habermasiana, considerando a necessidade do restabelecimento de uma postura dialógica e crítico-emancipatória na formação docente. As discussões são centralizadas criticamente na teia que amarra a educação aos interesses do sistema, especialmente na tarefa de adaptar a sociedade e os cidadãos à ordem econômica vigente.

Palavras-chave: Filosofia da educação. Formação. Competências. Dialogicidade.

\begin{abstract}
The article deals with the teacher's education on filosophy of education perspective, in order to meet the instrumental character present in the Pedagogy of Competences. This way, the goal was to analyze what are the possibilities and the limits of the competences for the teacher's education and the perspective of the theory of communicative action of Jürgen Habermas. The theoretical framework is based

\footnotetext{
" Doutor em Filosofia pela Universidade Federal do Rio Grande do Sul; Mestre em Educação pela Universidade Federal de Santa Maria.

** Mestre em Educação Brasileira pela Universidade Federal de Santa Maria; doutorando em Educação pela Universidade Federal de Santa Maria.
} 
on Haberma's hermeneutic-reconstructive approach, considering need to restore a dialogic and critical-emancipatory approach in teacher's education. The discussions are centered critically on the ell that ties education to system interests, especially in the task of adapting society and citizens to the existing economic order.

Keywords: Filosophy of education. Formation. Competencies. Exchange.

\section{INTRODUÇÃO}

Neste artigo, apresenta-se uma discussão crítico-filosófico sobre a Pedagogia das Competências, a qual foi instituída como fundamento teórico nas reformulações da composição curricular da educação brasileira nas últimas décadas. Essa teorização serviu para a modelagem dos sistemas de avaliação governamental brasileira pelo Instituto Nacional de Estudos e Pesquisas (INEP), como, entre outros, o Exame Nacional do Ensino Médio (ENEM), o Exame Nacional de Desempenho de Estudante (Enade), os Parâmetros Curriculares Nacionais do Ensino Médio (PCNEMs) e as Diretrizes Curriculares Nacionais do Ensino Médio (DCNEMs).

O problema consiste em identificar as implicações desse novo modelo curricular para a formação docente, inicial e continuada; esta última precisa acontecer em qualquer tempo e lugar ao longo do exercício da profissão. No entanto, quando ocorrem alterações radicais nas políticas para a educação, como a que substitui a Pedagogia por Objetivos pela Pedagogia das Competências, a formação precisa ser intensificada e acelerada nas duas modalidades. Nesse contexto, ela se torna o espaço necessário de reflexão sobre a elaboração do redesenho do currículo do ensino médio e para a reescrita do Projeto Político Pedagógico (PPP) da escola, dialogando com as DCNEMs e com as experiências dos professores e coordenadores pedagógicos em serviço. O diálogo visa criar e recriar um espaço para a reflexão coletiva sobre a prática docente no contexto da gestão democrática da escola e da prática pedagógica exigida na nova modalidade.

Uma das tarefas da formação inicial e continuada é possibilitar a compreensão das Diretrizes Curriculares Nacionais (DCNs), configurando a importância da participação de todos os sujeitos do processo educativo na reescrita do Projeto Político Pedagógico (PPP) da escola. Isso implica realizar discussões que orientam o (re)desenho do currículo, promovendo o diálogo e a mediação entre os participantes. Nesse contexto, a temática da formação docente provoca complexas reflexões a respeito das competências profissionais idealizadas para o desempenho da docência, em um tempo em que as mudanças político-econômicas e socioculturais da sociedade 
atual reclamam por transformações estruturais e estratégicas da educação. Contudo, como em qualquer empreendimento humano, é necessário avaliar criteriosamente os impactos e a amplitude que as mudanças poderão tomar. É preciso ter presente que as reformas realizadas apressadamente, sem um tempo para que se possa discutir, analisar e planejar a educação, podem ser instituídas autoritariamente, produzindo consequências marcadas pelo improviso, podendo afetar negativamente todos os setores nela envolvidos.

A análise da proposta da Pedagogia das Competências implica, portanto, buscar respostas para alguns questionamentos emergentes da própria prática, remetendo à investigação radical dos fenômenos para compreender os seus desdobramentos. Porém, segundo levantamentos realizados na literatura educacional, o reconhecimento da Pedagogia das Competências na educação está ocorrendo em três direções básicas: inovação (TERRAZZAN et al., 2008), recontextualização (SILVA; LOPES, 2007) ou tecnificação (TREVISAN, 2011) da formação humana. Nesses modelos de recepção há uma clara adesão ou receio de submissão de um polo a outro do conhecimento, com atitudes como as de aceitação ou de crítica ao esvaziamento, ou mesmo, à fuga da teoria pela prática. Entretanto, considera-se, por hipótese, que uma rejeição crítica ou a sua adesão irrefletida pura e simplesmente são saídas inócuas para o problema. A diretriz consiste em reverter, por um lado, os dilemas da compreensão separada da teoria e da prática na formação encetada pela Pedagogia das Competências. Ao privilegiar o polo da prática em detrimento da teoria, essa proposta construiu uma estrutura assimétrica de reconhecimento, na medida em que esvaziou a prática de sentido e a transformou em procedimento exclusivamente técnico e praticista, visto que esqueceu a teoria e o significado da educação promovida aos auspícios da reflexão sobre a formação mais ampla.

À luz dos esclarecimentos alcançados com a investigação do problema é possível propor o seguinte questionamento: em que medida a teoria comunicativa de Jürgen Habermas abre possibilidades de ampliação do horizonte de compreensão da Pedagogia das Competências, marcadamente instrumental, e como essa reformulação pode impactar positivamente a formação docente? A hermenêutica habermasiana, colocada na perspectiva metodológica, auxilia o pesquisador a lidar com a diversidade de compreensões teóricas dialogicamente construídas (DEVECHI; TREVISAN, 2010). A reconstrução visa perceber a ação comunicativa que se encontra por trás das normas que determinam, por vezes, o sentido da teoria investigada.

Desse modo, as abordagens hermenêutico-reconstrutivistas colocam-se como uma espécie de síntese de elementos positivos das precedentes, aproveitando 
os aspectos "críticos" e "evolutivos" das dialéticas e a preocupação com as categorias "contexto", "mundo da vida" e "compreensão" das fenomenológico-hermenêuticas; é por esse motivo que alguns autores a consideram hermenêutica crítica. Para elas, o sujeito é comunicativo e objetiva o consenso. Os significados resultam dos acordos construídos pragmaticamente por uma comunidade de argumentação, estando o caráter crítico na aceitação ou não das pretensões de validade do declarante (DEVECHI; TREVISAN, 2010, p. 153).

Assim, cabe investigar inicialmente, do ponto de vista da Filosofia da Educação, qual o contexto originário da Pedagogia das Competências para compreender melhor a sua proposta curricular para a educação brasileira. Busca-se conhecer, com isso, como ela está estruturada como proposta educacional e quais as suas implicações para a formação dos professores. Em seguida, considerando o problema demarcado, analisar quais as possibilidades e os limites das competências para a formação docente na perspectiva da abordagem reconstrutiva de Jürgen Habermas. Por fim, por meio da linguagem discursiva ou argumentativa, investigar a possibilidade de romper com os limites de um saber teórico fragmentado e/ou absoluto vigente na proposta, em favor da pluralidade compreensiva que a hermenêutica proporciona. Essas questões, em linhas gerais, orientam a busca de fundamentação teórica da temática em foco e auxiliam na condução das reflexões por um caminho argumentativo que pretende ser coerente com o delineamento metodológico demarcado.

\section{GÊNESE DA PEDAGOGIA DAS COMPETÊNCIAS}

A formação como processo educativo se desenvolve de acordo com os interesses, os valores, as necessidades e as exigências da sociedade em determinado tempo e lugar. Nessa dinâmica, que envolve a relação entre sociedade e educação, ou, mais especificamente, entre trabalho e educação, há muitos interesses em jogo. Não somente o Estado como responsável direto, mas em termos globais da esfera político-econômica (Banco Mundial, Fundo Monetário Internacional, Organização das Nações Unidas), das instituições, como a família e a escola, todos alimentam expectativas positivas em relação à qualidade da educação na formação dos cidadãos. As reformas educacionais brasileiras dos últimos tempos, ao perseguirem essa noção de qualidade, acabaram por adotar a Pedagogia das Competências influenciadas pelas ideias de César Coll e Philippe Perrenoud, persistindo com a sua influência sobre a prática pedagógica e a formação docente até hoje. 
O termo Pedagogia das Competências é oriundo da França e remonta ao ensino técnico, no qual, segundo Ramos (2002, p. 221),

[...] em vez de se partir de um corpo de conteúdos disciplinares existentes, com base no qual se efetua escolhas para cobrir os conhecimentos considerados mais importantes, parte-se de situações concretas, recorrendo-se às disciplinas na medida das necessidades requeridas por essas situações.

O ponto de partida das ações pedagógicas nessa perspectiva procura articular o contexto das vivências do aluno com atenção especial às temáticas de seu interesse, transpondo-as para dialogar com o conhecimento relativo a cada disciplina da composição curricular das diferentes etapas de ensino, de acordo com as escolhas recortadas do seu contexto. Nesse percurso, o professor direciona o processo de construção do conhecimento para a prática, com ênfase na didática, nos métodos e nas práticas de ensino que orientam a aprendizagem.

Em termos de análise semântica, o termo competência adquire diferentes sentidos, em contextos distintos. Às vezes, ele é associado à noção de desempenho (performance) em muitas áreas (economia, trabalho, formação e educação) e, nessa trajetória, vem substituindo outras noções, antes dominantes, como a noção de saberes e conhecimentos na esfera educativa, ou, como dito anteriormente, de qualificação na esfera do trabalho (RAMOS, 2002). Tais noções aos poucos perderam sua posição central e, associadas a competências, sugerem outras conotações a serem esclarecidas em seu uso atual.

O conceito de competência proposto por Perrenoud (1999, p. 7) trouxe um novo olhar sobre as práticas pedagógicas e sobre a compreensão do termo pedagógico. Ele reconhece que "são múltiplos significados do termo competência", mas limita-se a apresentar a sua definição como "[...] uma capacidade de agir eficazmente em um determinado tipo de situação, apoiada em conhecimentos, mas sem limitar-se a eles." A adoção das competências como base para as reformas curriculares e como horizonte normatizador das políticas públicas da educação brasileira acompanha um movimento mundial, mapeado por Nóvoa (2011, p. 3) em seu surgimento, do seguinte modo:

Nos anos oitenta e noventa, sobretudo nesta última década, foi-se impondo um outro conceito, competências, que passou a dominar a cena educativa. Elaborado teoricamente por autores de referência, tem tido um papel importante nas reformas curriculares, adaptando-se bastante bem aos novos discursos-práticas da "empregabilidade" e da "formação ao longo da vida". Todavia, apesar das inúmeras justificações e contrajustificações, não conseguiu libertar-se das suas origens comportamentalistas e de cariz técnico-instrumental. 
A ampliação das horas práticas nos cursos de formação docente está relacionada, nessa perspectiva, ao deslocamento da centralidade do processo de ensino, do conhecimento para a aprendizagem. A ênfase na prática exige que o professor construa as competências instrumentais, sem as quais encontraria dificuldades para operacionalizar a aprendizagem de acordo com as novas exigências. Mas, ao tomar o termo competência em seu sentido originário de "qualificação" advindo da educação profissionalizante, e ao universalizar seu uso para todas as formas de educação, não se está reduzindo-o a um mero instrumento de reprodução da mão de obra para o mercado?

Segundo Santomé (2011, p. 184), “[...] os sistemas educacionais são o grande instrumento através do qual se levaram adiante os processos de imperialismo cultural, uma das principais estratégias de opressão." Dominados pelo imperialismo cultural $^{1}$, sentem-se definidos a partir de fora e assimilam uma rede de significados dominantes, produzidos por pessoas que não se identificam com eles e vice-versa (SANTOMÉ, 2011). Por isso, quando se fala em cultura, a partir das instituições escolares, como categoria de análise e valoração, ela carrega implicitamente, em maior ou menor grau, funções políticas, entre as quais, a de reestruturação da própria sociedade. Isso exige uma atenção especial dos professores para que não sejam manipulados por esse poder no qual se encontram envolvidos.

Portanto, a "[...] tarefa de formar e profissionalizar educadores, particularmente em sociedades fortemente desiguais e subordinadas ao mercado global excludente, como a sociedade brasileira" (FRIGOTTO, 1996, p. 93), é um grande desafio para os sistemas de formação de professores, porque estes se veem obrigados a corresponder às demandas do processo de reestruturação produtiva em curso. Os altos índices de desemprego, a exclusão social, a baixa qualidade dos produtos e serviços e tantas outras frustrações sociais receberão a alcunha de "fracasso escolar", pois a avaliação feita é que a escola não ofereceu as condições para o êxito social. Logo, percebe-se que a função social da escola é direcionada ao atendimento das demandas do mercado.

Assim, ao avançar as discussões em direção à teia que amarra a Pedagogia das Competências aos interesses do sistema (político, econômico e social), é repassada à educação a incumbência de promover as mudanças necessárias para adaptar a sociedade e os cidadãos à ordem econômica emergente. Apresenta-se, dessa forma, a formação de professores como vetor para o reordenamento social, à medida que sua ação pedagógica deve articular a relação entre trabalho e sociedade, preparando as futuras gerações para o mercado produtivo. O professor, como ator social inserido na lógica do sistema, protagoniza essa formação repassando os fundamentos e os valores atinentes à educação, os 
quais estão expressos nas DCNs. O conceito de competência está, portanto, vinculado à racionalidade instrumental que mobiliza conhecimentos para a ação, para a solução de problemas em situações novas no contexto do mundo do trabalho.

A lógica da Pedagogia das Competências busca, desse modo, integrar o indivíduo ao mercado, isto é, “[...] quem quiser alcançar um mínimo de independência pessoal terá de concentrar todo o esforço no aperfeiçoamento das condições que o acesso ao mercado de trabalho exige.” (FLICKINGER, 2010, p. 179). E quando, por alguma razão, não há ingresso do indivíduo nos postos de trabalho, busca-se algum culpado, entre os quais a escola, por não ter qualificado o cidadão adequadamente.

As incursões preliminares nas veredas da reflexão filosófica sobre a Pedagogia das Competências explicitam que ainda persistem posturas no contexto educacional que remontam a um viés de entendimento da racionalidade moderna, sobretudo quando se toma a ciência e a técnica como soberanas frente à natureza e à cultura, alijando a humanidade de dispor de seu potencial para outros fins, que não sejam reduzidos aos apelos da razão instrumental. Na sociedade capitalista, o conhecimento se justifica como "[...] um investimento para a ação e está associado ao saber-fazer proveniente da experiência, ao lado dos saberes mais teóricos tradicionalmente valorizados na lógica da qualificação, o que faz surgir novas competências.” (PEREIRA, 2009, p. 76).

A utilização do termo competências na educação, na prática, equivale a retornar ao tecnicismo, considerando que “[...] a noção de competência não substitui ou supera o conceito de qualificação.” (PEREIRA, 2009, p. 76). Esse fundamento traz consequências para o ordenamento educacional à medida que interfere na autonomia pedagógica das escolas e dos professores e na gestão educacional em geral, exercendo certo controle sobre cada setor.

É oportuno admitir que, tendo seu germe na relação trabalho/sociedade, a Pedagogia das Competências traz mudanças nas políticas para a formação básica e formação continuada dos professores. Mantém-se uma forte implicação da educação com o mercado por meio de um esforço para que sustente a formação de novos trabalhadores que tenham o perfil desejado, pois “[...] cabe à educação de qualidade a formação de capital humano² eficiente para o mercado.” (DIAS; LOPES, 2003, p. 1156). Compreender essa dinâmica é de fundamental importância à medida que as diretrizes para a formação estão sendo propostas, ao que parece, com o intuito de preparar o professor para se enquadrar em um novo modelo de escola, cujo ensino possa formar um aluno que corresponda e se adapte, sobremaneira, às transformações econômicas, tecnológicas, políticas e sociais da sociedade contemporânea. 
Assim, a educação é tomada como reprodutora da matriz cultural da sociedade capitalista, sendo afetada por princípios individualistas marcados pela competitividade, ditados pelo capital e que são postos como hegemônicos, à revelia dos ideais humanitários reclamados por uma nova racionalidade. Dessa forma, ficando atrelada a esse modelo e sendo reprodutora de tal ordem, como tal, ela está sendo instrumento de legitimação de uma racionalidade que toma o homem em sua dimensão orientada para o desenvolvimento de competências e habilidades para atividades práticas no âmbito da produção.

A política educacional para a formação docente no Brasil busca estruturar um novo formato para os cursos de licenciatura, na perspectiva de produzir um perfil docente ajustado à lógica da reestruturação produtiva do trabalho no mundo globalizado. A flexibilização na produção exige perfis de trabalhadores genéricos e maleáveis para atuar no lugar do trabalhador "qualificado", treinado para exercer bem uma única função (PEREIRA, 2009). Isso implica mexer com a estrutura educacional em termos de formação, ou seja, “[...] formar o cidadão para adaptar-se com flexibilidade às novas condições de ocupação ou aperfeiçoamento." (BRASIL, 1998). Está implícito o objetivo de preparar indivíduos para competir por postos de trabalho no atual sistema capitalista que se apresenta em constante mutação.

Em âmbito educacional, isso implica a reorientação dos currículos, com cortes nos conteúdos das humanidades e artes e hipervalorização das ciências exatas e conteúdos tecnológicos e ênfase no fazer. A formação do cidadão é fragmentada e se restringe a produzir capital humano com conhecimentos e habilidades para encontrar lugar no mercado, em detrimento de uma cidadania que prima pela formação humana e que se preocupa com a justiça e a equidade em nossas sociedades (SANTOMÉ, 2011). Contraditoriamente a esse ideal, as humanidades, representadas nas disciplinas de Filosofia, Literatura, Sociologia, Música, Arte ou Educação Física, que poderiam contribuir para formar essa visão de ser humano, por exemplo, perderam terreno, como se pode observar na "Declaração de Moscou"3 (Art. 13). Esta recomenda, para as políticas educacionais, elevar os padrões em Matemática, Ciências, Tecnologia e idiomas estrangeiros. É nesse contexto que a proposta de educar por competências se orienta para produzir efeitos em torno da nova "nomenclatura" apresentada como um projeto educacional "novo". O fato de "ser novo" pode levar ao falso "encantamento", como lembra Santomé (2011, p. 189):

O discurso das competências se torna, da mesma forma que a Odisséia de Homero, o "canto das sereias" ou propaganda para entreter os professores, os quais, apesar de dedicar muitas horas para se esclarecerem sobre seu significado e operatividade, 
acabarão se dando conta de que assim seus problemas não são resolvidos, nem muito menos as dificuldades e a falta de interesse de muitos estudantes, pelo conhecimento.

Um dos perigos para os seguidores do "canto das sereias" é sucumbir na armadilha da linguagem das competências. Trata-se de esquecer o homem como prioridade e imprimir esforço para melhorar unicamente as técnicas, as metodologias e a didática, tirando o foco do conhecimento e investindo na dimensão prática/operativa da aprendizagem, no conhecimento tecnológico instrumental, esquecendo que a educação por natureza e essência tem como fim último formar o humano no homem.

No entanto, a educação não apenas é reprodutora da vida social, mas também transformadora, à medida que realiza o movimento que rompe com o convencional e institui o novo. Por estar imbricada com o sistema ${ }^{4}$ e sendo protagonista da formação cultural, ela transita na teia que interliga o sistema ao mundo da vida (HABERMAS, 1989). Dessa maneira, ela não somente pertence ao sistema político do Estado, o qual possui um sistema educacional a ele atrelado e dele dependente. Isso implica um esforço para restabelecer o lugar da autonomia dos sujeitos pela via argumentativa no contexto da educação e uma das possibilidades busca suporte na teoria da ação comunicativa de Habermas.

\section{A ABORDAGEM HERMENÊUTICA NOS PROPÓSITOS DA AÇÃO COMUNICATIVA}

A hermenêutica do conceito de formação oferece suporte interpretativo para a compreensão dos significados atribuídos aos conceitos e teorias a ela ligados, constituindo-se em uma importante forma de abordagem das temáticas da educação. Por isso, é importante esclarecer sua concepção originária para entender o seu uso no contexto em estudo.

A noção de formação em sua dinâmica sofre rupturas ou reformas de acordo com os interesses de uma sociedade, em seu tempo. Revendo a hermenêutica do conceito de formação, o termo clássico, de certo modo aceito até hoje, por exemplo, traz as influências das noções de Paideia e Bildung. A formação entendida como Bildung apresenta uma forte conotação herdada do pensamento iluminista que se encaminha para formar sujeitos autônomos, autodeterminados (FLICKINGGER, 2010). Essa conotação é reforçada pelo pensamento apresentado por Wilhelm Von Humboldt, para quem, segundo a versão de Flickinger (2010, p. 177), “[...] a Bildung do homem é a formação máxima e mais proporcional possível de suas forças, no intuito 
de integrá-las em um todo." Essa concepção, quando apropriada pelos Estados Liberais, e traduzida em políticas educacionais, implica criar as condições favoráveis para a sua realização, de tal forma a proporcionar o autodesenvolvimento e a conquista da liberdade tanto social quanto cultural do indivíduo. Essa noção centraliza no sujeito o conhecimento, característica marcante do iluminismo kantiano referendado no conceito de Bildung.

No entanto, o conceito de formação que domina o paradigma atual se distancia cada vez mais das raízes clássicas da Paideia e da Bildung. O homem não se coloca mais como o centro das preocupações e a educação parece estar aprisionada pela dinâmica de um processo de transformações sociais que lhe utiliza como um meio e não mais como um fim. Nesse panorama, “[...] a concepção de formação como diretriz para os esforços educativos vê-se profundamente afetada e até mesmo transformada por essa dinâmica." (FLICKINGGER, 2010, p. 178).

$\mathrm{O}$ afastamento de princípios e valores herdados da tradição grega (Paideia), sem que fossem analisados na perspectiva da humanização como um valor universal, reduz o próprio homem a uma simples mercadoria. A introdução do modelo voltado para a produção econômica, centrado no individualismo e na competição, herança da sociedade industrial capitalista, é percebida como possibilidade para as mudanças necessárias na educação. Da mesma forma, outras correntes centradas no sujeito perdem de vista a formação do ser para pôr em evidência o ter, com foco predominantemente alicerçado na busca do saber fazer e com fortes influências nas políticas educacionais brasileiras das últimas décadas, como visto até aqui. É nessa rotina de tentativas, muitas vezes fracassadas, outras timidamente revisitadas, que se observa o "[...] entendimento reducionista do conceito de formação no sistema atual da educação que se encaminha para o risco de uma alienação crescente em relação às experiências do mundo da vida." (FLICKINGGER, 2010, p. 179).

O enfoque crítico-filosófico remete à herança da razão iluminista formatada na perspectiva instrumental e que foi alvo das teorias críticas por reduzir a realidade ao que está apresentado objetivamente e possa ser comprovado matematicamente, pelas ciências experimentais.

Esse paradigma de racionalidade científica representa o conhecimento do mundo através de um saber calcado nas condições de estabilidade e causalidade, de modo que afirma ser possível prever o comportamento dos fenômenos e, dessa maneira, controlá-los, transformando o mundo em uma grande máquina. (BASSALOBRE, 2007, p. 174). 
Em torno desse paradigma, a humanidade depositou confiança na ciência apostando na possibilidade de que ela pudesse proporcionar bem-estar e um padrão de vida social, sem desigualdades, miséria ou pobreza. Contudo, no percurso da história, a humanidade sofreu as consequências nefastas do uso inconsequente da razão e da ciência, ao fragmentar o conhecimento e dar margem à ação política dos governantes que se serviam dela sem responsabilidade. Os desvios na utilização do conhecimento científico provocaram um posicionamento crítico de filósofos como Adorno e Horkheimer, os quais denunciam as distorções e o reducionismo que simplificam o uso da razão ao âmbito instrumental, ao imediatamente apresentado.

Na redução do pensamento a uma aparelhagem matemática está
implícita a ratificação do mundo como sua própria medida. O
que aparece como triunfo da racionalidade objetiva, a submis-
são de todo ente ao formalismo lógico, tem por preço a subordi-
nação obediente da razão ao imediatamente dado. (ADORNO;
HORKHEIMER, 1985, p. 138).

Com isso, "[...] o esclarecimento que expressava com a idéia do Iluminismo um potencial emancipatório, se esfacela ao se converter no mito do progresso técnico-científico." (GOMES, 2007, p. 124). Essa postura faz com que a humanidade "[...] pague um preço altíssimo pelo aumento compulsivo de um poder que se auto-aliena, se autoconserva e, conseqüentemente, afasta a possibilidade da crítica e da emancipação.” (GOMES, 2007, p. 124).

Analisando a postura de Habermas sobre as críticas à modernidade, percebe-se que ele não discorda totalmente delas, mas afirma que há um potencial da razão que ainda não foi explorado, referindo-se à capacidade emancipatória que ela teria para superar suas limitações. Em poucas palavras, pode-se dizer que a própria razão crítica teria o "antídoto" para corrigir os desvios e retomar o caminho perdido em seu projeto original desde que submetida a um processo de reconstrução.

Ele apresenta a teoria da ação comunicativa como parâmetro para o entendimento das relações humanas na sociedade atual e propõe a racionalidade intersubjetiva e dialógica, com forte apelo de inserção em uma ética contextualizada sem abrir mão dos princípios universais presentes na moral kantiana (MARTINI, 2010). Os fundamentos habermasianos, constantes na teoria comunicativa, embora não possam ser aplicados de forma linear ao contexto de compreensão da ação educativa, contribuem para o entendimento da situação educacional e para o restabelecimento de uma perspectiva crítica da educação, podendo perpassar a formação docente. Mesmo que não tenha sido pensada especificamente para o contexto educacional, mas para a sociedade em geral, ela oferece uma reflexão pertinente para a compreensão da educa- 
ção atual à medida que abre a possibilidade de fundamentar as reflexões sobre a mútua implicação existente entre sociedade e educação.

Nas relações intersubjetivas há oportunidades de identificar princípios ou pressupostos para "o agir racional", os quais possam orientar o pensar e o fazer do homem como ser em construção, ciente da necessidade de atribuir sentido à sua existência e à sua ação no mundo da vida. Se para Habermas a questão fundamental da filosofia é a razão humana, a tarefa principal do filósofo é refletir e analisar o potencial que a razão tem para explicar o mundo e orientar a ação humana.

Habermas (2003, p. 39-40), ao explicar o que entende por hermenêutica, expressa essa compreensão reconstrutiva do sentido, ao distingui-la da perspectiva meramente observável dos fenômenos:

Toda expressão dotada de sentido - seja um proferimento (verbal ou não verbal), um artefato qualquer como, por exemplo, um utensílio, uma instituição ou um documento - pode ser identificada numa perspectiva bifocal, tanto como uma ocorrência observável, quanto como a objetivação inteligível de um significado. Podemos descrever, explicar ou predizer um ruído que equivalha ao proferimento vocal de uma frase falada, sem ter a menor idéia do que esse proferimento significa. Para captar (e formular) seu significado, é preciso participar de algumas ações comunicativas (reais ou imaginadas) no curso das quais se empregue de tal modo a frase mencionada que ela seja inteligível para os falantes e ouvintes e para os membros eventualmente presentes da mesma comunidade lingüística.

Partindo desse esclarecimento, pode-se conhecer a dinâmica dos termos na forma inteligível de um significado, de forma cognitiva, conceitual, a partir da interação comunicativa. A hermenêutica, vista desse modo, é a ação de elucidar um conceito e sua implicação com algo no mundo sobre o qual o conceito se refere e, por isso, compreender o que é dito por alguém exige, necessariamente, a participação no agir comunicativo.

No sentido epistemológico, a hermenêutica constitui-se em uma teoria geral da interpretação e uma importante metodologia para as pesquisas nas Ciências Humanas. Ela tem sua vertente e fundamento na reflexão de Heidegger sobre a facticidade,5 segundo a qual o ser humano se encontra, desde sempre, inserido no tempo e é incapaz de se livrar desse horizonte (FLICKINGER, 2010). A partir dessa perspectiva, Hans Gadamer desenvolveu a hermenêutica filosófica e reagiu à concepção de homem sujeito e dominador da história, contrapondo-lhe a ideia de homem sujeito à história e, em especial, à linguagem. Desse modo, o homem se reconhece como parte da história e da linguagem que são elementos instituintes de seu próprio ser. 
Habermas (2003, p. 41) acrescenta a essa discussão a ideia de que “[...] a hermenêutica considera a linguagem, por assim dizer, em ação, a saber, da maneira como é empregada pelos participantes com o objetivo de chegar à compreensão conjunta de uma coisa ou a uma maneira de ver comum.” O caráter dinâmico da linguagem pode ser percebido "[...] quando um falante profere algo dentro de um contexto quotidiano, ele se refere não somente a algo no mundo objetivo, mas ao mesmo tempo a algo no mundo social e a algo existente no mundo próprio, subjetivo, do falante." (HABERMAS, 2003, p. 41). Assim, a conexão entre o proferimento e o mundo ocorre na perspectiva interativa do falante e do ouvinte.

A opção pela abordagem hermenêutica nas pesquisas educacionais (GOERGEN, 2010) viabiliza a superação dos limites impostos pela racionalidade cartesiana, transferindo para a dimensão da linguagem e da intersubjetividade o processo de produção de conhecimento e da compreensão inerente à experiência da linguagem. Nesses termos, a verdade não é um enunciado conceitual com pretensões absolutas, mas o resultado sempre provisório de um processo dialógico aberto e construtivo a respeito de suas pretensões de verdade. Assim, a postura dialógica faz emergir novas possibilidades interpretativas e argumentativas, ampliando a participação dos sujeitos de modo a avançar, retomar e reconstruir conceitos em uso que tenham sentidos ambíguos ou polissêmicos.

\section{FORMAÇÃO DOCENTE NA PERSPECTIVA DA AÇÃO COMUNICATIVA}

As diretrizes para a formação docente (ao preterir a prática à teoria) menosprezam o fato de que que ela está profundamente implicada com o desenvolvimento da razão, por ser instrumento para o discernimento dos problemas que afetam a sociedade. Por meio da crítica da razão é possível perceber a existência das contradições e potencialidades no seu percurso histórico até a contemporaneidade. É na formação da racionalidade historicamente situada que a humanidade encontra os fundamentos para dirimir os conflitos, orientar a ação e alcançar os objetivos almejados, evitando tornar-se um mero produto de seu tempo.

O desafio da reconstrução teórica e conceitual do conceito de competências inicia-se com as noções pré-teóricas e intuitivas, presentes no horizonte de inteligibilidade do seu uso em determinado contexto (como na educação ou no trabalho). Quando, no entanto, um intérprete (ou pesquisador) recorre à reconstrução racional em busca de entendimento de como essa teoria foi apropriada pela educação, desempenha uma ação 
comunicativa para compreender e refazer o percurso e o sentido da teoria em estudo, depurando-a de possíveis equívocos em seu uso ou interpretações equivocadas em sua aplicação. Então, as intuições teóricas que iniciaram a investigação são reconstruídas e, nesse processo, o conhecimento antes intuitivo passa a ser racional. Nesse cenário, a hermenêutica passa a alavancar a busca da verdade, ainda que provisória, imprimindo um caráter dinâmico, por estar sempre em processo de construção e reconstrução a cada nova possibilidade interpretativa que surge no horizonte da linguagem, não como monólogo, mas como ação comunicativa entre sujeitos competentes.

Ao buscar na teoria da ação comunicativa as contribuições para repensar os limites e obstáculos à consecução das competências, destaca-se como fundamental, no paradigma do entendimento recíproco, a atitude performativa dos participantes da interação que coordenam seus planos, ao se entenderem sobre algo no mundo (HABERMAS, 2011, p. 414). Dessa forma, o conceito habermasiano do agir comunicativo nas questões que envolvem a educação remete à compreensão do conceito de racionalidade comunicativa.

O conceito de racionalidade comunicativa leva consigo conotações, que em última instância, se remontam à experiência central da capacidade de se unir sem coações e de formar consenso através de uma fala argumentativa em que os participantes superam a subjetividade inicial de suas concepções e, à mercê da comunidade de convicções racionalmente motivadas, se asseguram simultaneamente da unidade do mundo objetivo e da intersubjetividade do tecido da vida social em que se movem. (HABERMAS, 2011, p. 506).

A racionalidade comunicativa põe a linguagem em uma posição central na experiência comunicativa que leva os participantes de um debate a desconstruírem suas próprias convicções à medida que, engajados em um ato de fala, submetem seus argumentos ao crivo dos demais participantes. O diálogo com outros participantes que empenham sua fala para conquistar uns aos outros em torno de argumentos pressupõe respeito mútuo, reconhecendo o outro como sujeito de fala e em condições de igualdade com os demais participantes. A disputa ocorre no âmbito da linguagem e o resultado esperado é o consenso em torno do melhor argumento, diante do qual se rendem às convicções inicialmente apresentadas pelos falantes. Nessa lógica, é fundamental para os participantes da ação comunicativa que não se perca de vista a necessidade de superar a subjetividade inicial de suas concepções sob o risco de reproduzir as noções do senso comum ou do determinismo cultural aprisionado pelas tradições.

Esse parece ser o caminho para a reconstrução de teorias ou propostas como a Pedagogia das Competências, a qual se apresenta de forma impositiva e unilateral 
ao sistema educacional e carrega a influência de interesses econômicos e políticos alinhados ao projeto neoliberal de sociedade. Frente a essa realidade, a ação comunicativa articula e dinamiza esse processo de desconstrução/reconstrução cultural, ao apresentar a competência comunicativa como instrumento para transpor tais limitações e abrir horizontes sempre renovados para repensar a educação na perspectiva humana.

A competência comunicativa convertida em ação comunicativa por meio da linguagem transcende os limites da instrumentalidade do mundo do trabalho para assumir a centralidade das interações humanas, aconteçam no mundo do trabalho ou no mundo da vida. Assim, os horizontes são ampliados para além dos fins instrumentais do mercado, restabelecendo o lugar do ator como fim nos processos educativos. Esse lugar não se restringe aos ofícios a serem desempenhados por força da divisão do trabalho, mas aos múltiplos contextos que envolvem o humano no mundo da vida, como o político, o social, o cultural, o religioso, o ético e o estético.

\section{DESAFIOS PARA A FORMAÇÃO POR COMPETÊNCIAS}

A reflexão crítico-filosófica neste escrito produz um duplo sentimento em relação às necessidades da formação. Primeiramente, a angústia toma conta quando, aos poucos, desvenda-se a educação como parte de um sistema político e econômico que se apropria dela como meio para obter os resultados desejados, mediante um discurso ideológico envolvente, alienante. Em segundo lugar, a certeza de que a formação de uma consciência crítica, dialógica, pautada pelo reconhecimento do outro, potencializa desvelar as teias alienantes colocadas no horizonte dos processos formativos, como armadilhas de uma lógica que pretende homogeneizar e alienar a todos. Portanto, há como dirimir tais limitações desde que elas sejam identificadas e abordadas com atitude crítica.

A tentativa de reconstrução do conceito de competências instiga a problematizar os valores que poderiam ser apresentados para alicerçar, fortalecer e ampliar os horizontes da formação dos professores para além do enfoque instrumental. Além disso, orientar a gestão da formação de professores no âmbito de uma ética da justiça, ética do bem comum, assumindo uma postura crítica diante das políticas educacionais. Em que medida a educação por competências poderia executar essa tarefa é um horizonte ainda a ser descortinado, portanto.

No relatório da UNESCO para a educação do século XXI, encontra-se algumas pistas para responder a essa dúvida. 
Para podermos compreender a crescente complexidade dos fenômenos mundiais e dominar o sentimento de incerteza que suscita, precisamos, antes, adquirir um conjunto de conhecimentos e, em seguida, aprender a relativizar os fatos e a revelar sentido crítico perante o fluxo de informações. A educação manifesta aqui, mais do que nunca, o seu caráter insubstituível na formação da capacidade de julgar. (DELORS, 2010, p. 47).

Delors (2010) enfatiza a necessidade de adquirir um conjunto de conhecimentos para que sirva de referencial para as interlocuções com o mundo da vida. Para ele, um fenômeno como o da Globalização "dificulta o engajamento do indivíduo", que fica perplexo diante da complexidade do mundo, "que altera suas referências habituais". Em síntese, a mundialização apresenta a dura realidade da qual somente podem participar apenas alguns privilegiados.

Esse cenário também cria uma expectativa da formação em relação à educação para o trabalho, considerando a necessidade de inserir o indivíduo nesse novo contexto. Quais competências cabem à escola desenvolver, no processo de construção de conhecimento do cidadão? A partir dessa perspectiva, busca-se a reflexão e a reconstrução conceitual do projeto de formação continuada de professores, tomando a teoria habermasiana como horizonte epistemológico, potencializando sua contribuição no desenvolvimento da capacidade de julgar.

A ênfase exagerada na prática, que fundamenta e orienta as reformas educacionais brasileiras do final do século passado, trouxe como consequência o recuo da teoria na formação inicial dos docentes. Essa lacuna amplia a necessidade de uma formação suplementar, na modalidade de formação continuada. Nela, acrescenta-se o conhecimento e a experiência que advém das práticas, fortalecidos por uma fecunda reflexão teórica capaz de reinventar, recriar e refundamentar a prática, a fim de qualificá-la com as experiências significativas vividas e compartilhadas pelos participantes do processo formativo.

O deslocamento do foco da educação da teoria para a prática repercute de forma direta na formação à medida que aumentam as horas de atividades práticas, voltadas para a aprendizagem da didática e das técnicas de ensino em prejuízo da fundamentação teórica e da construção de conhecimentos mais fundamentados. A valorização dos saberes do cotidiano, sem promover a articulação destes com os fundamentos teóricos, acaba por reproduzir o saber do senso comum, relegando-os ao nível da opinião. A busca de saída dos limites da Pedagogia das Competências exige a adoção de uma postura crítica e filosófica, uma postura epistemológica capaz de restabelecer o entendimento de que a teoria e a prática precisam caminhar juntas. 
É preciso que elas dialoguem em condições de igualdade, pois uma não se sustenta sem a outra. As competências e as habilidades para o fazer, quando não inspiradas na teoria, levam a uma experiência fragmentada, distanciada da dimensão epistemológica, científica e técnica, reduzindo o sujeito à condição reificada. Avançar para além da ênfase instrumental exige que a formação seja gestada na perspectiva integral e que recupere a dimensão ética e estética da Paideia grega, repensando o sentido teleológico da formação.

A certeza de que já não existem "verdades absolutas" em educação infere que não há como traçar um único caminho. Logo, ele precisa ser construído dialogicamente sem perder de vista o contexto cultural de origem e as especificidades de cada participante, em relação a uma realidade global e dinâmica. A perspectiva apresentada pela Pedagogia das Competências é reducionista por estabelecer como meta competências universais, genéricas, configurando um perfil de cidadão homogêneo, capaz de se enquadrar nas estruturas e necessidades do mundo do trabalho, participando ativamente do processo produtivo. Por vincular a noção de competência associada à ideia de qualificação profissional, torna-se afeita aos ditames da racionalidade instrumental e põe o mercado como fim da educação, reduzindo o humano à força de trabalho.

\section{CONCLUSÃO}

Neste artigo, propôs-se a discutir a ideia da reformulação do dilema teoria e prática desenvolvido pela educação brasileira, cristalizado nas normativas sobre a formação de professores, a partir da reflexão sobre uma Filosofia da Educação inspirada na teoria da ação comunicativa. Buscam-se, assim, novas perspectivas de interação entre a formação teórica e a formação prática na área da Educação, compreendendo a docência pelo horizonte hermenêutico.

Para além das competências instrumentais, reconhecidas como necessárias para o mundo do trabalho, requer-se ampliar o seu universo de compreensão para o mundo da vida. É nessa dimensão que entra a competência comunicativa, abrindo possibilidades dialógicas e de entendimento mútuo por acolher a diversidade de entendimentos para aprimorá-los mediante o processo dialógico. Nesse contexto, emergem as competências individuais expressas por meio da linguagem e que transcendem os limites do instrumental.

Portanto, é necessário incluir os valores da formação cultural, como a sensibilidade à natureza, educando para a percepção de suas formas de vida e para o cuidado em relação à sua preservação; no que diz respeito ao caráter intersubjetivo 
e comunicativo nas relações humanas, pautar as relações pela valorização e reconhecimento do outro, considerando que as diferenças percebidas no outro potencializam o sentido de pertença à humanidade; construir conceitos e conhecimentos em uma perspectiva comunicativa e dialógica em busca de estabelecer o consenso; e, por último, reconhecer a importância do erro e da ilusão na produção do conhecimento (GOERGEN, 2000). Esses desafios implicam resgatar e ampliar o potencial crítico da razão humana como condição de realização da sua própria natureza. Isso sugere reconhecer que ela não pode ser reduzida e confinada à lógica instrumental, a serviço da ciência e da técnica operadas no mundo do trabalho. Urge ampliar o esforço para a construção das competências cognitivas, intelectuais e humanas, sem as quais não haveria a emancipação do homem das limitações que a racionalidade instrumental lhe impõe. Essa parece ser uma preocupação permanente que desafia a todos aqueles que pensam, agem e se preocupam com a educação em busca do processo de evolução social, considerando todas as suas contradições e potencialidades.

Uma vez esclarecidos os limites da racionalidade instrumental, é possível perceber que Habermas procura restabelecer uma dimensão da razão humana ampliada e que foi esquecida pela predominância dessa racionalidade. Ao desenvolver a teoria da racionalidade comunicativa, ele pretende

[...] restaurar a natureza integral da razão pela qual a humanidade, não somente pode promover formas cada vez mais sofisticadas de controle e manipulação da realidade objetiva, mas desenvolver-se socialmente pelo estabelecimento de formas racionais de vida social e de formação de individualidades cada vez mais autônomas. (MÜHL, 2010, p. 28).

A racionalidade comunicativa precisa estar presente na formação docente, pois por meio dela é possível desenvolver o potencial crítico, reflexivo e reconstrutivo como um recurso fundamental para a formação de uma sociedade aberta, em que as individualidades possam se orientar de forma autônoma e livre. A educação, quando orientada por essa teoria, pode levar à emancipação e à autonomia por considerar a todos como participantes legítimos e em condições de igualdade.

A partir do estudo realizado, será possível apontar algumas aproximações formativas com a realidade pesquisada, pois tanto nas reivindicações teóricas quanto nas práticas pedagógicas se pode compreender a preocupação e o interesse com a produção significativa do conhecimento. Não se busca uma formação baseada em um conhecimento empírico, puramente técnico, mas em um conhecimento interpretativo acerca do mundo, da cultura, do cotidiano, preocupado com a sua abordagem crítico-hermenêutica. A reivindicação da prática na formação de professores pode ser revista 
à luz da teoria da ação comunicativa, na medida em que busca produzir um conhecimento ampliado, voltado para a formação de sujeitos críticos e argumentativos. A compreensão da formação indica, portanto, a necessidade de reposicionamento do método técnico de construção de competências para uma educação que valorize o seu reconhecimento intersubjetivo.

A proposta de reformulação da compreensão dicotômica entre a teoria e a prática, intencionada neste artigo, poderá promover outras possibilidades de articulação desse dilema na formação, evitando, assim, anomalias na compreensão do processo. As competências para isso se diluem em um panorama mais amplo, não apenas enfatizando o raciocínio lógico matemático e o domínio dos processos científicos e tecnológicos que envolvem o mundo do trabalho. A formação de professores nessa ótica se volta para as possibilidades de crescimento do debate sobre a diversidade cultural, com a pluralidade que emerge da valorização das formações cultural, política, ética e estética, presentes no mundo da vida.

Notas explicativas

${ }^{1}$ Imperialismo cultural: Imposição de princípios e valores de acordo com os interesses ideológicos do Estado vistando a alienar os cidadãos a uma única cultura, impondo-a como hegemônica e homogênea a tais princípios e valores.

${ }^{2}$ Formação de capital humano: Tal teoria apregoa existir uma estreita relação entre desenvolvimento econômico e desenvolvimento educacional, sendo este último considerado fator que incrementa a produtividade do trabalho.

${ }^{3}$ Declaração de Moscou foi o documento que resultou de reuniões de ministros da educação de países membros do G8, em 02 de junho de 2006, em Moscou.

${ }^{4}$ É parte do sistema e a ele está envolvida por ser burocraticamente regida e organizada por leis.

${ }^{5}$ Entende-se como o determinismo existencial e a condição do homem, no qual se encontra dependente e sempre imerso em uma tradição.

\section{REFERÊNCIAS}

ADORNO, T. W.; HORKHEIMER, M. Dialética do esclarecimento. Rio de Janeiro: JZE, 1985.

BASSALOBRE, J. N. A educação em tempos de crise paradigmática: análise da proposta de Edgar Morin. Cadernos de Educação, Pelotas, n. 29, p. 173-189, jul./ dez. 2007.

BRASIL. Ministério da Educação. Resolução CEB n. 03, de 26 de junho de 1998. Institui as Diretrizes Curriculares Nacionais para o Ensino Médio. Disponível em: $<$ http://portal.mec.gov.br/cne/arquivos/pdf/rceb03_98.pdf $>$. Acesso em: 20 jun. 2015. 
DELORS, J. Educação: Um Tesouro a Descobrir. Relatório para a UNESCO da Comissão Internacional sobre educação para o século XXI. UNESCO, 2010. Disponível em: <http://unesdoc.unesco.org/images/0010/001095/109590por.pdf > . Acesso em: 18 jun. 2015.

DEVECHI, C. P. V.; TREVISAN, A. L. Sobre a proximidade do senso comum das pesquisas qualitativas em educação: positividade ou simples decadência? Rev. Bras. de Educ., Rio de Janeiro, v. 15, n. 43, jan./abr. 2010.

DIAS, R. E.; LOPES, A. C. Competências na formação de professores no Brasil: o que (não) há de novo. Educ. Soc., Campinas, v. 24, n. 85, p. 1155-1177, dez. 2003.

FLICKINGER, H. G. A caminho de uma Pedagogia Hermenêutica. Campinas: Autores Associados, 2010.

FRIGOTTO, G. A formação e a profissionalização do educador: novos desafios. In: SILVA, T. T.; GENTILI, P. (Org.). Escola S. A.: quem ganha e quem perde no mercado educacional do neoliberalismo. Brasília, DF: CNTE, 1996.

GOERGEN, P. L. Competências docentes na educação do futuro: anotações sobre a formação de professores. Nuances (Faculdade de Ciências e Tecnologias UNESP), Presidente Prudente, v. 6, p. 1-9, out. 2000.

GOERGEN, P. L. Prefácio. In: FLICKINGER, H. G. A caminho de uma pedagogia hermenêutica. Campinas: Autores Associados, 2010.

GOMES, L. R. Educação e consenso em Habermas. Campinas: Alínea, 2007.

HABERMAS, J. Consciência moral e agir comunicativo. Rio de Janeiro: Tempo Brasileiro, 1989.

HABERMAS, J. Consciência moral e agir comunicativo. 2. ed. Rio de Janeiro: Tempo Brasileiro, 2003.

\section{HABERMAS, J. Teoría de la acción comunicativa. Complementos y estúdios} prévios. Madrid: Catedra, 2011.

MARTINI, R. M. F. As dimensões de ação e discurso do trabalho do professor: enfoques de Habermas e Ricouer. In: PEREIRA, M. A.; FLIPPOZZI, R. M.; PITANO, S. C. (Org.). Filosofia e Educação: articulações, confrontos e controvérsias. Pelotas: Ed. UFPEL 2010.

MÜHL, E. H. Racionalidade e formação: uma abordagem habermasiana. In: PEREIRA, M. A.; MARTINI, R. M. F.; PITANO, S. C. (Org.). Filosofia e Educação: articulações, confrontos e controvérsias. Pelotas: Ed. UFPEL, 2010. 
NÓVOA, A. Novas disposições dos professores: a escola como lugar de formação. In: CONGRESSO DE EDUCAÇÃO DO MARISTA DE SALVADOR (Bahia, Brasil), 2., 2011, Salvador, Anais... Salvador, 2011. Disponível em: <http://docs.di.fc. ul.pt/bitstream/10451/685/1/21205_ce.pdf>. Acesso em: 04 jun. 2014.

PEREIRA, S. M. Educação básica e formação docente no contexto das exigências do mundo do trabalho: a formação por competências em análise. Cadernos de Educação, Pelotas, v. 33, p. 57-79, maio/ago. 2009.

PERRENOUD, P. Construir as competências desde a escola. Porto Alegre: Artes Médicas Sul, 1999.

RAMOS, M. N. A pedagogia das competências: autonomia ou adaptação? 2. ed. São Paulo: Cortez, 2002.

SANTOMÉ, J. T. Evitando o debate sobre a cultura no sistema educacional: como ser competente sem conhecimento. In: SACRISTÁN, J. G. et al. Educar por competências: o que há de novo? Porto Alegre: Artmed, 2011.

SILVA, D. B.; LOPES, A. C. Competências nas políticas de currículo: recontextualização pela comunidade disciplinar de ensino de física. Revista Brasileira de Pesquisa em Educação em Ciências, Atibaia, v. 7, n. 1, 2007.

TERRAZZAN, E. et al. Configurações curriculares em cursos de licenciatura e formação identitária de professores. Revista Diálogo Educacional, Curitiba, v. 8, n. 23, p. 71-90, jan./abr. 2008.

TREVISAN, A. L. Filosofia da Educação e formação de professores no velho dilema entre teoria e prática. Educ. rev., Curitiba, n. 42, p. 195-212, 2011.

Recebido em: 04 de abril de 2015

Aceito em: 01 de julho de 2015

Endereço para correspondência: Avenida Roraima, 1000, Camobi, 97105-900, Santa Maria, Rio Grande do Sul, Brasil; trevisanamarildo@gmail.com 
